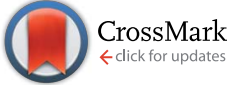

Cite this: Chem. Sci., 2015, 6, 6556

\title{
Reactive species involved in the regioselective photooxidation of heptamethine cyanines $\uparrow$
}

\author{
Roger R. Nani, ${ }^{a}$ James A. Kelley, ${ }^{a}$ Joseph Ivanic ${ }^{\star b}$ and Martin J. Schnermann*a
}

Heptamethine cyanines are important near-IR fluorophores used in many fluorescence applications. Despite this utility, these molecules are susceptible to light-promoted reactions (photobleaching) involving photochemically generated reactive oxygen species (ROS). Here, we have sought to define key chemical aspects of this nearly inescapable process. Near-IR photolysis of a model heptamethine cyanine leads to the regioselective oxidative cleavage of the characteristic polyene. We report the first quantitative analysis of the major reaction pathway following either photolysis or exposure to candidate ROS. These studies clearly indicate that only singlet oxygen $\left({ }^{1} \mathrm{O}_{2}\right)$, and not other feasible ROS, recapitulates the direct photolysis pathway. Computational studies were employed to investigate the regioselectivity of the oxidative cleavage process, and the theoretical ratio is comparable to observed experimental values. These results provide a more complete picture of heptamethine cyanine photooxidation, and provide insight for the design of improved compounds for future applications.

Received 3rd July 2015

Accepted 6th August 2015

DOI: $10.1039 /$ c5sc02396c

www.rsc.org/chemicalscience

useful are the heptamethine cyanines, which contain a 7-carbon linker connecting two indolenine heterocycles. The absorption and emission maxima of these molecules are generally around $800 \mathrm{~nm}$, occupying the center of the near-IR window where tissue penetration is maximized and autofluorescence is minimized. ${ }^{7}$ One example, indocyanine green, is an FDA approved diagnostic agent used in numerous clinical contexts and new variants continue to be developed for advanced optical applications. ${ }^{\mathbf{8 - 1 1}}$

The photodegradation of cyanines is a frequent issue that can impede fluorescence readout. Not only deleterious, this chemistry has been used deliberately for productive applications. We recently demonstrated that the photooxidation of C4'-dialkylamine heptamethine cyanines could be used as the central element of a biologically compatible near-IR uncaging approach. ${ }^{12}$ Other investigators have employed the ROSmediated oxidation of cyanines for sensing methods. ${ }^{\mathbf{1 3 , 1 4}}$ Prior studies examining cyanine photodegradation have shown that photolysis leads to oxidative cleavage of the polyene linker to provide carbonyl products (eqn (1)). ${ }^{15-19}$ These studies, while providing a key initial description of this process, have either not addressed or provided conflicting information regarding the observed products and the nature of the oxidant(s). Other uncertain aspects of cyanine reactivity include the effect of key ROS and the basis of the high regioselectivity observed in the oxidative cleavage reaction. Clear answers to these fundamental questions would enable efforts that seek to expand the utility of heptamethine cyanines. 

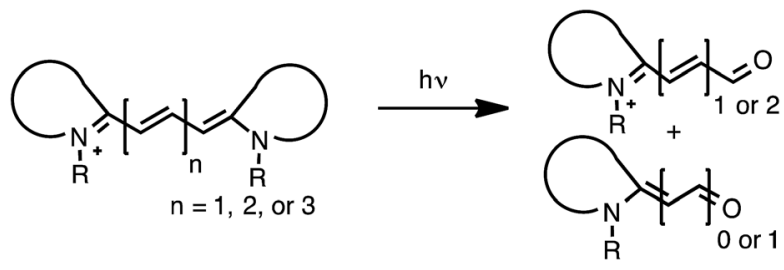

To address these questions, we have employed a combination of experimental and theoretical approaches. Our experimental efforts have centered on mass spectral studies and the first quantitative accounting of cyanine oxidation products, using both direct irradiation and exogenous reactive oxygen species. Photolysis at the cyanine absorption maximum induces C-C cleavage at two of the four feasible reaction sites in the cyanine polyene. We show that only singlet oxygen $\left({ }^{1} \mathrm{O}_{2}\right)$, generated either chemically or through photosensitization, and not other common ROS, provides the photolysis products in similar yield. We have also carried out the first quantum mechanical computational analysis of the major oxidative cleavage reaction pathway. Our computational studies have provided a clear justification for both the origin of the regioselectivity (i.e. the relative stability of possible intermediate dioxetanes) and the relative ratio of the observed products for the major ${ }^{1} \mathrm{O}_{2}$-dependent pathway. In total, we have defined key aspects of this photodegradation process, which is encountered in nearly any application of these broadly employed molecules.

\section{Results and discussion}

\section{Photooxidation: experimental results}

We sought to address the regioselectivity of the photooxidative C-C cleavage, which, in the case of symmetrical heptamethine cyanines, could lead to four regioisomeric product mixtures. Prior reports on several different heptamethine cyanine substrates provided conflicting data with three studies suggesting that oxidative cleavage occurs at a single terminal position in the cyanine polyene, ${ }^{15,20,21}$ another cleavage occurs at only a central position in the cyanine polyene, ${ }^{22}$ and two recent studies, including our own, observing cleavage at two sites. ${ }^{12,23}$ Certainly some of this apparent ambiguity is derived from the slightly different substrates and conditions used between the different studies. Moreover, these studies often employed only mass spectral data to assign the photooxidative products, and in no instances were reaction yields determined.

We have chosen 1, which represents the simplest heptamethine indocyanine, as a model system for our efforts. ${ }^{24}$ To accurately measure yields of reactions run at low micromolar concentrations, we employed triplicate HPLC analysis calibrated using standard curves generated from independently prepared standards of previously known 2 and 6 (see ESI $\dagger$ ). Exposing a solution of $1\left(50 \% \mathrm{MeCN} / \mathrm{H}_{2} \mathrm{O}, 20 \mu \mathrm{M}\right)$ to modest fluence $\left(20 \mathrm{~mW} \mathrm{~cm}^{-2}\right)$ of $740 \mathrm{~nm}$ light for 2 hours produces 2 and 6 in 57\% and 12\% yields, respectively (Fig. 1A). We have also carried out HRMS studies and detected $\mathbf{1}$ and 7, validating that oxidative cleavage occurred between $\mathrm{C} 2 / \mathrm{C}^{\prime}{ }^{\prime}$ and $\mathrm{C} 2{ }^{\prime} / \mathrm{C} 3^{\prime}$, as well as $\left[\mathbf{1}+\mathrm{O}_{2}\right]$ ions. Careful analysis of the HRMS spectra found no evidence for the compounds derived from cleavage between $\mathrm{C}^{\prime} / \mathrm{C} 2^{\prime}$ (4 and 5), and $\mathrm{C} 3^{\prime} / \mathrm{C}^{\prime}$ (8 and 9), or hydrolysis products thereof, supporting the notion that this reaction proceeds with high regioselectivity. We have also shown that 2 and 6 accumulate concurrently with the loss of the signal for $\mathbf{1}$ and that the ratio of the two intermediates $(\sim 5: 1)$ is essentially constant throughout the reaction (Fig. S1 $\dagger$ ). Control experiments have determined that these photoproducts are stable for the duration of the photolysis experiment. While we account for a majority $(\sim 70 \%)$ of the material through this method, there is a fraction of 1 that is not attributed to identifiable species. Despite attempts to purify and characterize other products using HPLC, we have not been able to account for the balance of the reaction mixture.

We have carried out further studies on $\left[\mathbf{1}+\mathrm{O}_{2}\right]$ ions to determine if these species represent dioxetane intermediates. As expected, the formation of these ions was observed only upon near-IR irradiation. MS/MS analysis following direct flow injection was performed to investigate accessible fragmentation pathways (Fig. 1B). ${ }^{25}$ Collision-induced dissociation (CID) of the $\left[\mathbf{1}+\mathrm{O}_{2}\right]$ ions generated a product ion spectrum containing highresolution masses that correspond to carbonyls $2\left([\mathrm{M}+\mathrm{H}]^{+}\right), 3$ $\left([\mathrm{M}]^{+}\right), \mathbf{6}\left([\mathrm{M}-\mathrm{H}]^{+},[\mathrm{M}+\mathrm{H}]^{+}\right)$and $7\left([\mathrm{M}]^{+}\right)$, among others. These results provide additional evidence to support the intermediacy of dioxetanes $\mathbf{1 0}$ and $\mathbf{1 1}$, as these represent the most reasonable structures of a $\left[\mathbf{1}+\mathrm{O}_{2}\right]$ mass that could fragment directly to the observed carbonyl products.

To investigate the oxidant in this reaction, we have examined the reactivity of $\mathbf{1}$ with independently generated ROS. Our efforts commenced with ${ }^{1} \mathrm{O}_{2}$, which was generated by two mechanistically distinct methods. The photosensitizer, tetraphenylporphyrin zinc (ZnTPP), is well established to cleanly form ${ }^{1} \mathrm{O}_{2}$ in high quantum yield $\left(\phi_{\Delta}=0.7\right)$ upon irradiation with $420 \mathrm{~nm}$ light. $^{26,27}$ This method afforded a similar product distribution of oxindole 2 (61-64\%) and aldehyde 6 (13-15\%) to that produced by direct cyanine excitation (entries 2 and 3, respectively, Table 1). Photolysis using only $420 \mathrm{~nm}$ light in the absence of a photosensitizer did induce photooxidation to form 2 and 6, albeit with dramatically slower kinetics ( $\sim 15$ fold) to that observed in the presence of catalytic ZnTPP (Fig. S2 $\dagger$ ). This result is consistent with a small $\left(\sim 2 \%\right.$ relative to the $\left.\lambda_{\max }\right)$ absorption of 1 at $420 \mathrm{~nm}$. To complement the photosensitizerdependent photooxidation, we examined the impact of ${ }^{1} \mathrm{O}_{2}$ generated via the thermal decomposition of endoperoxide $12 .^{28}$ We found that exposure of 1 to 200 equivalents of 12 at $34{ }^{\circ} \mathrm{C}$ in $50 \% \mathrm{MeCN}: \mathrm{H}_{2} \mathrm{O}$ produced a high yield of oxindole $2(71 \%)$ and aldehyde $6(10 \%)$, collectively. Thus, 2 and 6 are formed in similar yields through direct near-IR photolysis and from independently generated ${ }^{1} \mathrm{O}_{2}$, which was formed either thermally or photochemically. This observation provides significant support to the notion that ${ }^{1} \mathrm{O}_{2}$-mediated dioxetane formation is the major pathway involved in cyanine photooxidation. ${ }^{29}$ Photosensitized formation of ${ }^{1} \mathrm{O}_{2}$ is consistent with the small number of prior experimental measurements of heptamethine cyanine triplet state emission values (including one measurement on 1), which exceed the requisite $22.6 \mathrm{kcal} \mathrm{mol}^{-1}$ needed for ${ }^{1} \mathrm{O}_{2}$ energy transfer. ${ }^{30,31}$ 


\section{A. Photooxidation of Heptamethine Cyanine 1}
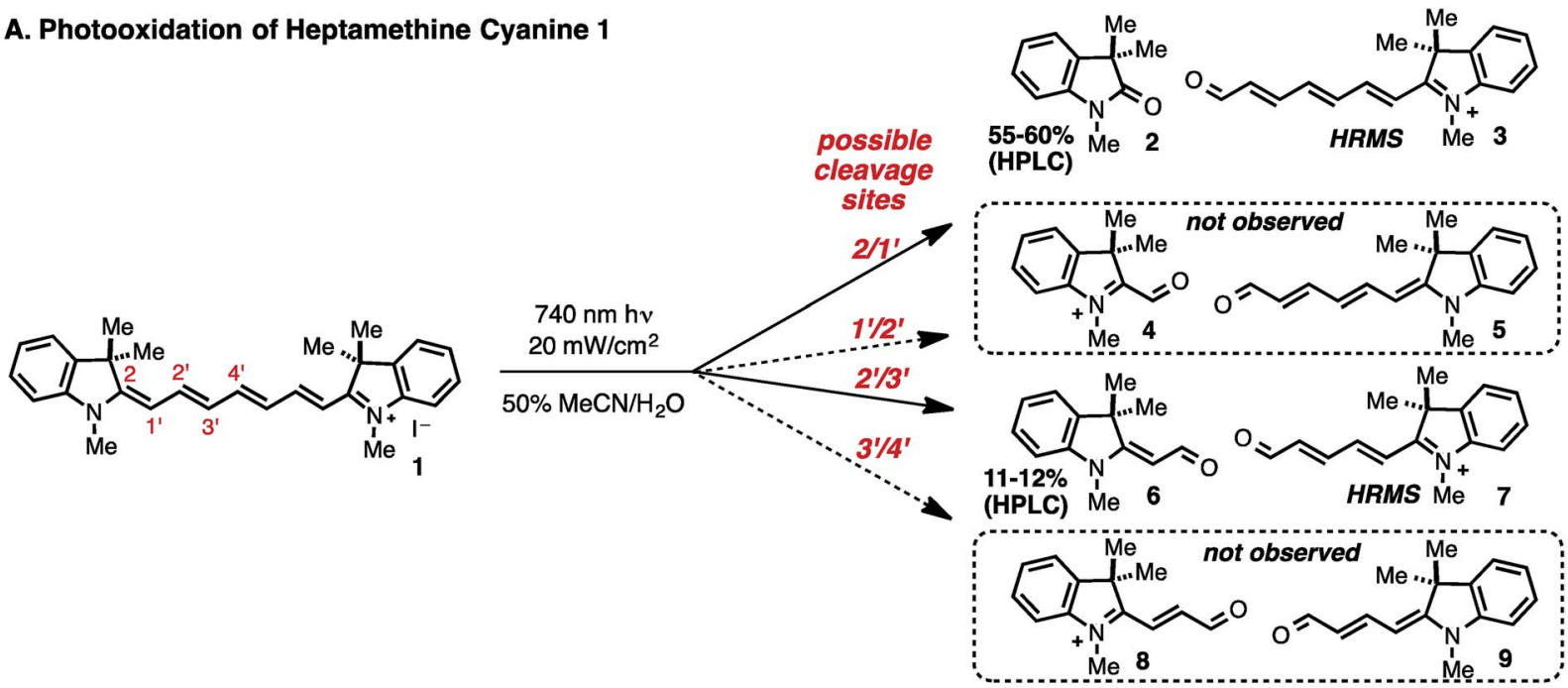

B. MS/MS Analysis of Dioxetane Intermediates

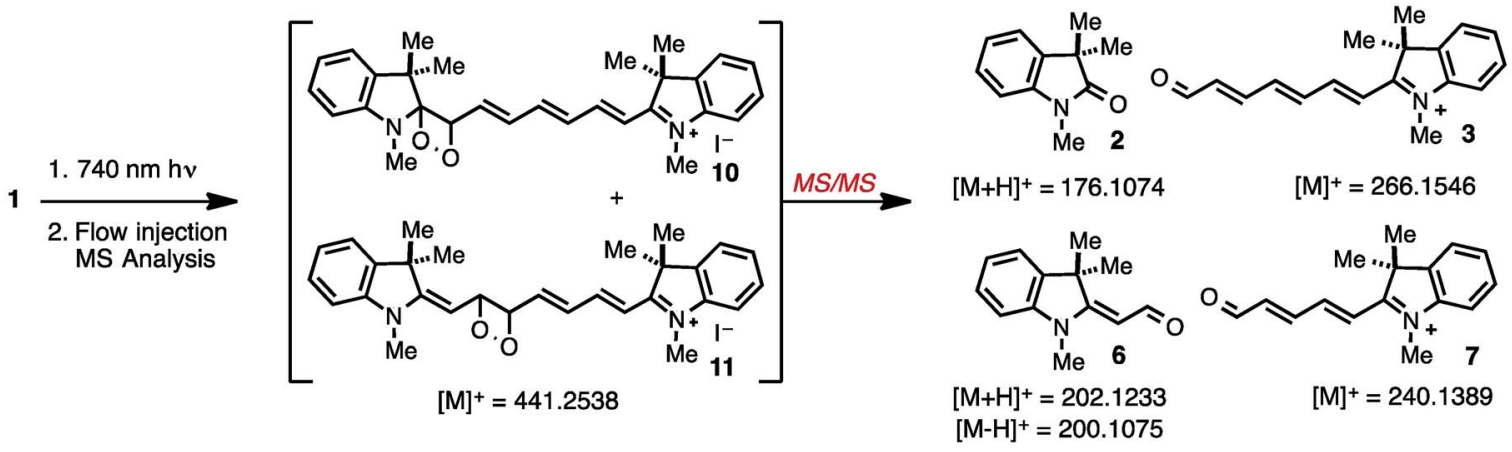

Fig. 1 (A) Photoproducts observed by HRMS upon $740 \mathrm{~nm}$ light irradiation of 1 and (B) MS/MS [1+O ${ }_{2}$ ] adducts.

It has been suggested that cyanine photodegradation may involve superoxide $\left(\mathrm{O}_{2}{ }^{-}\right)$, generated through electron transfer from the triplet state and, potentially, hydrogen peroxide $\left(\mathrm{H}_{2} \mathrm{O}_{2}\right)$ or hydroxyl radical $\left(\mathrm{OH}^{*}\right)$, formed as downstream products of
$\mathrm{O}_{2}{ }^{\cdot-} \cdot{ }^{17,18,20,32-35}$ To investigate this possibility, the reactivity of 1 with these ROS was examined. In the case of $\mathrm{OH}^{\cdot}$ (entry 1 , Table 2), 1 was consumed, but formed only trace quantities of 6 $(1-3 \%)$ and barely detectable quantities of $2(<0.5 \%)$. We have

Table 1 Yields of 2 and 6 upon reaction of 1 with photolysis or independently generated ${ }^{1} \mathrm{O}_{2}$

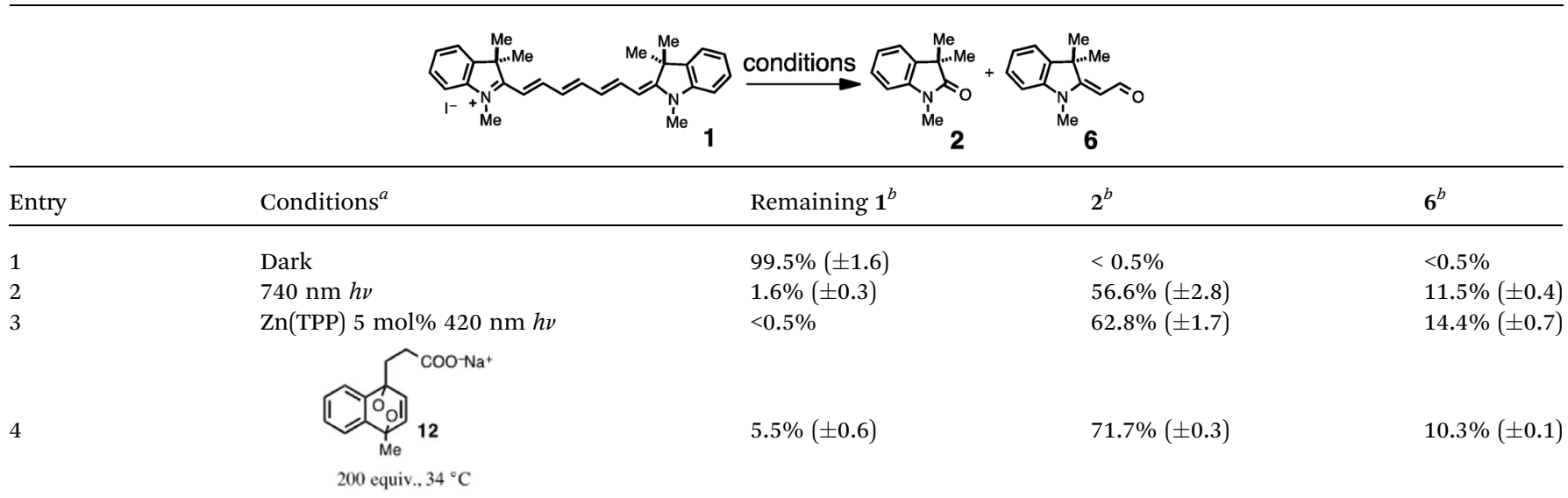

\footnotetext{
${ }^{a}$ Run at $22^{\circ} \mathrm{C}$ in $1: 1 \mathrm{MeCN}: \mathrm{H}_{2} \mathrm{O}$ unless noted otherwise. ${ }^{b}$ Determined by HPLC and reported in percent yield. Values are average of experimental triplicate. Error expressed as standard deviation in parentheses.
} 
been unable to identify any of the numerous species that appear to be formed (see ESI $\dagger$ for representative HPLC traces), suggesting that complex radical-mediated pathways are involved. In contrast, $\mathrm{O}_{2}{ }^{--}$and $\mathrm{H}_{2} \mathrm{O}_{2}$ largely do not react with 1 under neutral aqueous conditions, even at concentrations that exceed those attainable by photolysis. ${ }^{36}$ Critically, control experiments showed that compounds $\mathbf{2}$ and $\mathbf{6}$ were unaffected by these or the other ROS generating conditions shown in Table 2. These control experiments ensure that the observed product ratio is indicative of reactions involving $\mathbf{1}$, and not of further oxidation of 2 and 6. In total, these results indicate that $\mathrm{HO}^{\circ}, \mathrm{H}_{2} \mathrm{O}_{2}$, and $\mathrm{O}_{2}{ }^{\cdot-}$ are not likely the major components of direct cyanine photooxidation, with all three providing product mixtures that are clearly distinct from that obtained upon direct near-IR photolysis. The critical observation is that, while other ROS can generate modest yields of oxindole 2 , only ${ }^{1} \mathrm{O}_{2}$, formed either chemically or photochemically, is capable of generating 6 in conversion comparable to that generated by direct photolysis.

Recent studies have imaged oxidative flux by using oxidation of certain cyanines with biological ROS, specifically hypochlorite $(\mathrm{NaOCl})$, peroxynitrite $\left(\mathrm{ONOO}^{-}\right), \mathrm{OH}^{*}$, and $\mathrm{O}_{2}{ }^{--} \cdot \cdot^{\mathbf{1 3 , 1 4 , 3 7}}$ The yields of products obtained from such ROS could provide insights useful in future efforts to develop these methods. Reaction of 1 with $\mathrm{NaOCl}$ generated meaningful quantities of oxindole 2, and no measureable 6 (entry 6, Table 2). While exposure of 1 to $150 \mu \mathrm{M} \mathrm{NaONO}$ under basic conditions produced over $30 \%$ yield of 2 (entry 7 , Table 2 ), only trace amounts of 6 were observed. ${ }^{38}$ As with entry 1 , we were unable to identify any other oxidation products formed in entries 6 and 7 . Taken together with observations of Nagano and coworkers, ${ }^{13}$ these results provide additional evidence indicating that the reactivity of heptamethine cyanines is highly dependent on the ROS species.

\section{Regioselectivity: quantum mechanical computational study}

While the studies above clarified that the major photooxidation pathway of heptamethine cyanines involved singlet oxygen, the basis for the high regioselectivity of this process - with cleavage occurring at only two of four possible sites - was unclear. To address this, we pursued a computational approach. Although the distinctive optical properties of heptamethine cyanines have been examined computationally in several prior reports, ${ }^{39-43}$ our efforts are the first to examine the reactivity of cyanines.

As a first step, we computed the total reaction energies (electronic) for the four possible cleavage pathways using the B3LYP and MP2 methods with the 6-31G(d) basis set (see Methods section for full details). We point out that we cannot explicitly compute MP2 and B3LYP ${ }^{1} \Delta_{\mathrm{g}} \mathrm{O}_{2}$ energies since this electronic state is not a single-reference dominated wavefunction. As such, we have determined ${ }^{1} \Delta_{\mathrm{g}} \mathrm{O}_{2}$ energies by adjustments (adding experimental electronic energy splitting) to readily computed ${ }^{3} \Sigma_{\mathrm{g}}{ }^{-} \mathrm{O}_{2}$ energies (see Methods). A consequence of this limitation is that we are unable to compute Gibbs free energy changes for these reactions. The $\pi$ system of 1 is completely flat ( $C_{2 \mathrm{v}}$ point group) at the B3LYP level of theory but very slightly twisted ( $C_{2}$ point group) when using the MP2 method. We have considered both cis and trans isomers (about the end $\mathrm{C}-\mathrm{C}$ bond, where relevant) to identify the lowest energy product aldehydes. Fig. 2 clearly shows that all four reactions are significantly exothermic $\left(\Delta E_{e}<-50 \mathrm{kcal} \mathrm{mol}^{-1}\right.$ relative to reactants $1+{ }^{1} \Delta_{\mathrm{g}} \mathrm{O}_{2}$ ), with cleavage at the $\mathrm{C} 2 / \mathrm{C}^{\prime}$ and $\mathrm{C}^{\prime} / \mathrm{C}^{\prime}$ sites leading to the most favorable products, having B3LYPpredicted energies of $-89 \mathrm{kcal} \mathrm{mol}^{-1}$ and $-66 \mathrm{kcal} \mathrm{mol}^{-1}$, respectively. We also point out that the MP2 and B3LYP results are in excellent agreement. While the two experimentally observed cleavage pathways are also the most favored in absolute terms, the observation that all pathways are highly exothermic suggested that this explanation is incomplete.

The experimental results provided additional evidence to suggest that $\mathrm{O}_{2}$ addition and subsequent cleavage proceeds via dioxetane intermediates. ${ }^{\mathbf{4 4}}$ Accordingly, we investigated whether the energetics of dioxetane formation is responsible for the observed regioselectivity. In order to locate the absolute lowestenergy structures for each of the four possible intermediates, we performed geometry optimizations starting from a very large number of initial structures that comprehensively spanned the

Table 2 Reaction of 1 with various ROS and respective yields of 2 and 6

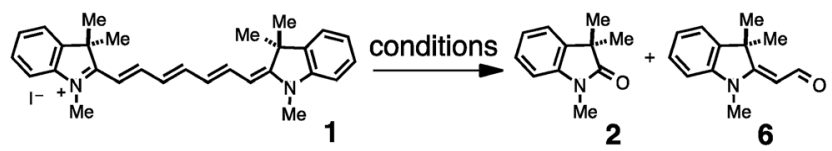

\begin{tabular}{|c|c|c|c|c|}
\hline Entry & Conditions $^{a}$ & Remaining $\mathbf{1}^{b}$ & $2^{b}$ & $6^{b}$ \\
\hline $1\left(\mathrm{HO}^{\bullet}\right)$ & $\mathrm{FeCl}_{2} 200 \mu \mathrm{M} \mathrm{H}_{2} \mathrm{O}_{2} 500 \mu \mathrm{M} \mathrm{NaHPO}{ }_{4} \mathrm{pH}=6$ & $3.4 \%( \pm 1.2)$ & $<2.7 \%( \pm 0.3)$ & $<0.5 \%$ \\
\hline $2\left(\mathrm{H}_{2} \mathrm{O}_{2}\right)$ & $\mathrm{H}_{2} \mathrm{O}_{2} 100 \mu \mathrm{M}$ PBS $\mathrm{pH}=7.4$ & $99.5 \%( \pm 0.5)$ & $<0.5 \%$ & $<0.5 \%$ \\
\hline $4\left(\mathrm{O}_{2}^{\cdot-}\right)$ & $\mathrm{KO}_{2} 100 \mu \mathrm{M}$ & $99.2 \%( \pm 1.1)$ & $<0.5 \%$ & $<0.5 \%$ \\
\hline $5\left(\mathrm{O}_{2}^{\cdot-}\right)$ & $\mathrm{KO}_{2} 1 \mathrm{mM}$ & $84.1 \%( \pm 0.2)$ & $10.6 \%( \pm 0.1)$ & $<0.6 \%( \pm 0.1)$ \\
\hline $6\left(\mathrm{ClO}^{-}\right)$ & NaOCl $100 \mu \mathrm{M}$ PBS pH $=7.4$ & $<0.5 \%$ & $19.5 \%( \pm 0.7)$ & $<0.5 \%$ \\
\hline
\end{tabular}

${ }^{a}$ Run at $22{ }^{\circ} \mathrm{C}$ in $1: 1 \mathrm{MeCN}: \mathrm{H}_{2} \mathrm{O}$ unless noted otherwise. ${ }^{b}$ Determined by HPLC and reported in percent yield. Values are average of experimental triplicate. Error expressed as standard deviation in parentheses. 


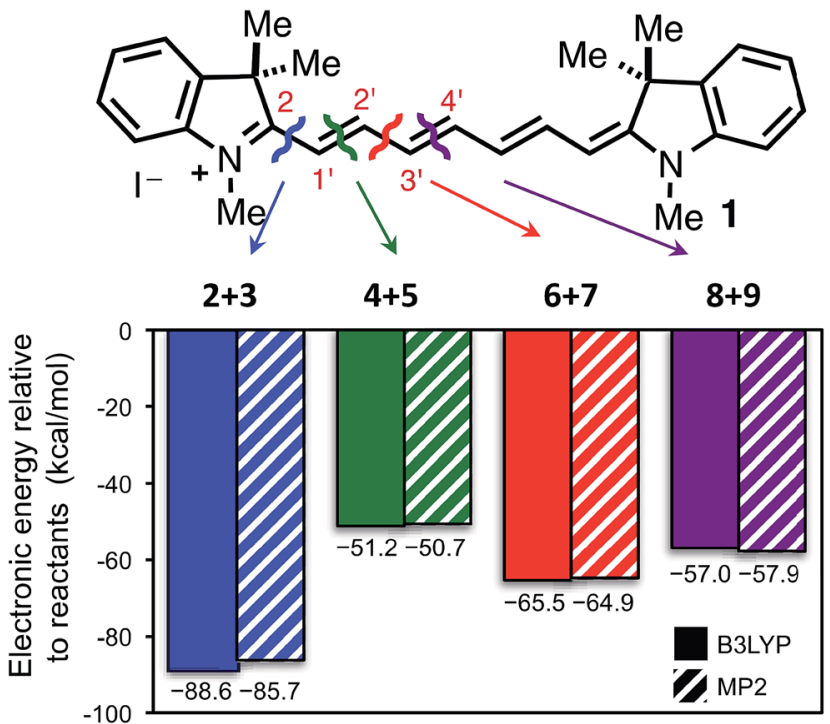

Fig. 2 Computed reaction energies (electronic) for the four possible cleavage pathways of $1+{ }^{1} \Delta_{\mathrm{g}} \mathrm{O}_{2} \rightarrow \mathrm{R}=\mathrm{O}+\left[\mathrm{R}^{\prime}=\mathrm{O}^{+}\right.$. Blue, green, red, and indigo indicate cleavage at $\mathrm{C} 2 / \mathrm{C1}^{\prime}, \mathrm{C1}^{\prime} / \mathrm{C2}^{\prime}, \mathrm{C} 2^{\prime} / \mathrm{C} 3^{\prime}$, and $\mathrm{C} 3^{\prime} / \mathrm{C} 4^{\prime}$ sites, respectively.

potential energy surfaces. For each type of dioxetane intermediate, the only structural restrictions applied were to conserve (i) the initial trans conformation of the two carbon atoms that bind $\mathrm{O}_{2}$ and (ii) the trans backbones of the carbon chains (to rings) starting from the carbon atoms immediately attached to the $\mathrm{C}(\mathrm{OO}) \mathrm{C}$ dioxetane unit. Our reasoning being that $\mathrm{O}_{2}$ addition is expected to occur with high stereoselectivity. This prediction follows from seminal studies by Turro and coworkers on reactions of related ene-carbamates with ${ }^{1} \mathrm{O}_{2}{ }^{45} \mathrm{~A}$ full description, with informative illustrations, of the structural degrees of freedom that have been considered is provided in the ESI. $\uparrow$ Geometry searches were performed independently at the MP2/6-31G(d) and B3LYP/6-31G(d) levels of theory and all discovered minima were confirmed by computations of vibrational frequencies. The numbers of minima located for each class of intermediate and method is summarized in Table 3. We find that the MP2 method predicts more minima for each intermediate class than B3LYP (no less than 21 for addition over $\mathrm{C}^{\prime} / \mathrm{C}^{\prime}$ ) and includes more dioxetane "twist" conformations and $N$-methyl proton orientations (typically staggered). The B3LYP/6-31G(d) method identified four minima for each intermediate except the second (addition over $\mathrm{C}^{\prime} / \mathrm{C2}^{\prime}$ ), for which five were discovered and in each case only one $\mathrm{N}$-methyl orientation was preferred (typically eclipsed).

Fig. 3 illustrates the lowest energy (electronic) B3LYP/6$31 \mathrm{G}$ (d) structures for each of the four possible intermediates. The lowest energy MP2 structures (provided in ESI $\dagger$ ) are commensurate except for $\mathbf{1 3}$ (addition over $\mathrm{C}^{\prime} / \mathrm{C}^{\prime}$ ), which differs by a $180^{\circ}$ rotation about the $\mathrm{C} 2-\mathrm{C}^{\prime}$ bond.

All 17 dioxetane intermediate minima located using the B3LYP/6-31G(d) method were also optimized using the larger cc-pVTZ basis set where lowest energy structures for each of 10, 11, 13 and 14 were commensurate to those shown in Fig. 3A.
Table 3 Number of minima located for each possible dioxetane intermediate ${ }^{a, b, c}$

\begin{tabular}{llllr}
\hline Method & $\begin{array}{l}\text { 10: } \\
\left(\mathrm{C} 2 / \mathrm{C}^{\prime}\right)\end{array}$ & $\begin{array}{l}\text { 13: } \\
\left(\mathrm{C}^{\prime} / \mathrm{C} 2^{\prime}\right)\end{array}$ & $\begin{array}{l}11: \\
\left(\mathrm{C}^{\prime} / \mathrm{C} 3^{\prime}\right)\end{array}$ & $\begin{array}{l}14: \\
\left(\mathrm{C}^{\prime} / \mathrm{C} 4^{\prime}\right)\end{array}$ \\
\hline MP2 & $12(6)$ & $6(6)$ & $18(9)$ & $21(12)$ \\
B3LYP & $4(4)$ & $5(5)^{d}$ & $4(4)$ & $4(4)$
\end{tabular}

${ }^{a}$ 6-31G(d) basis set used for minima searches. ${ }^{b}$ See Fig. 1A for carbon numbering scheme, whereby $\mathrm{CX} / \mathrm{CY}$ indicates $\mathrm{O}-\mathrm{O}$ addition locale. ${ }^{c}$ Numbers in parentheses do not consider $N$-methyl orientation. ${ }^{d}$ At the B3LYP/CCT level of theory one minimum optimizes to another leaving only four.

However, one of the intermediate $\mathbf{1 3}$ species optimized to another, leaving only four. Fig. 3B shows the stabilities (electronic) of the dioxetane intermediates relative to the reactants 1 $+{ }^{1} \Delta_{\mathrm{g}}{ }^{1} \mathrm{O}_{2}$. We find that the MP2/6-31G(d) and B3LYP/6-31G(d) results are comparable, predicting similar exothermic stabilities for each intermediate in the order $\mathbf{1 0}<\mathbf{1 1}<\mathbf{1 4}<\mathbf{1 3}$, although MP2 predicts a more stable (by $3.5 \mathrm{kcal} \mathrm{mol}^{-1}$ ) intermediate 10. When advancing to the B3LYP/cc-pVTZ level of theory, the energetic order of the intermediates is preserved, however, now only intermediates $\mathbf{1 0}$ and $\mathbf{1 1}$ are computed to be exothermic by $2.8 \mathrm{kcal} \mathrm{mol}^{-1}$ and $0.7 \mathrm{kcal} \mathrm{mol}^{-1}$, respectively. Therefore, the computational results indicate that ${ }^{1} \mathrm{O}_{2}$ addition and subsequent cleavage is energetically favored only via dioxetane intermediates $\mathbf{1 0}$ and 11. Not only does this prediction match which cleavage pathways are observed experimentally (C2/C1 $1^{\prime}$ and $\left.\mathrm{C}^{\prime} / \mathrm{C}^{\prime}\right)$, it also correctly indicates that cleavage at (C2/C1') should be the major reaction pathway.

We have also calculated Gibbs free energies $\left(G_{298}\right)$ at the MP2/ 6-31G(d) and B3LYP/6-31G(d) levels of theory for all discovered minima (B3LYP/6-31G(d) $G_{298}$ corrections were used to estimate B3LYP/cc-pVTZ $G_{298}$ energies). For the two methods MP2/6$31 \mathrm{G}(\mathrm{d})$ and B3LYP/cc-pVTZ it can be the case that the lowest $G_{298}$ structure for an intermediate can vary from the corresponding lowest electronic energy structure and these differences are shown in Fig. S12 and S13. $†$ Fig. 3C shows computed relative free energies $\left(G_{298}\right)$ of the dioxetane intermediates where 10 remains the most stable. We find that when going from the MP2/6-31G(d) to B3LYP/6-31G(d) to B3LYP/cc-pVTZ levels of theory that intermediates 11, 13, and $\mathbf{1 4}$ are successively stabilized. Our most reliable prediction, B3LYP/cc-pVTZ, indicates that $\mathbf{1 1}$ is most competitive with 10 , lying only $1.5 \mathrm{kcal} \mathrm{mol}^{-1}$ higher. At room temperature $(298 \mathrm{~K})$, this energy difference amounts to a Boltzmann ratio of $\sim 13: 1$ that should transfer to the corresponding cleavage products $2+3$ and $6+7$. This theoretical prediction is remarkably similar to the experimentally determined ratio of $\sim 5: 1$, especially when taking into account that solvent effects have not been considered and energy margins are of the order of a kcal mol${ }^{-1}$. In fact, the experimentally observed ratio translates to an energy difference (at $298 \mathrm{~K}$ ) of $0.95 \mathrm{kcal} \mathrm{mol}^{-1}$ which is really not very different from $1.5 \mathrm{kcal} \mathrm{mol}^{-1}$ when one acknowledges that quantum chemical accuracy of $1 \mathrm{kcal} \mathrm{mol}^{-1}$ is typically reached only with benchmark methods that are currently impossible for this sized system. 
A<smiles>CC(C)C=CC=CC=COCC1([N+]([O-])([O-])O)c2ccccc2N(C)C1(C)C</smiles>
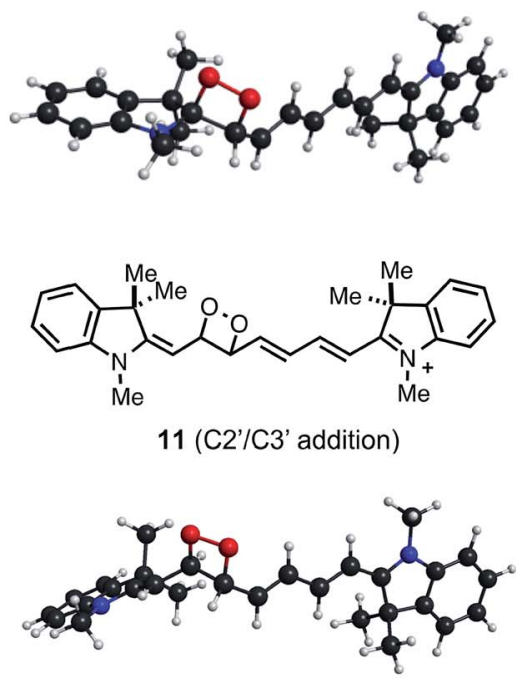

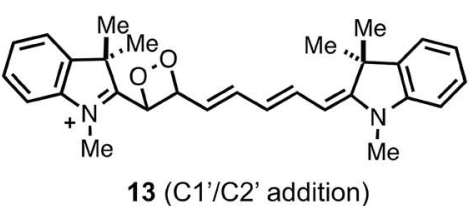

13 (C1'/C2' addition)
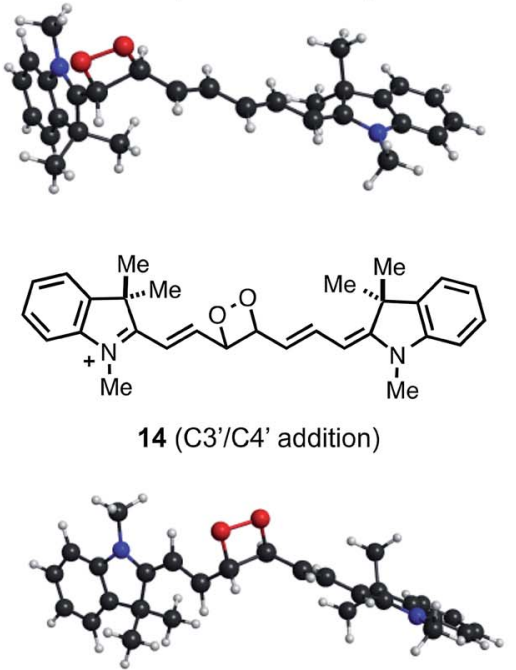

B
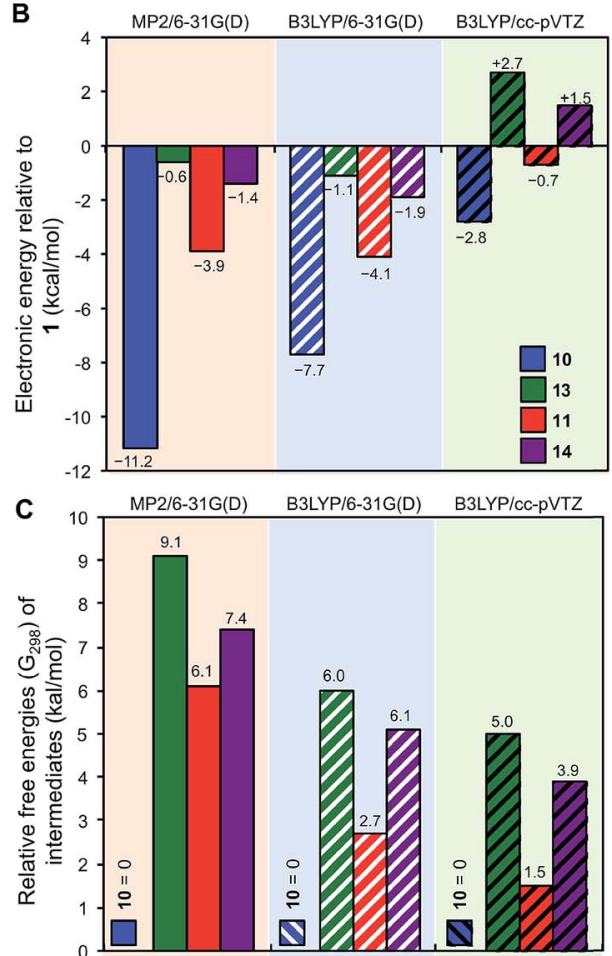

Fig. 3 Lowest energy (electronic) B3LYP/6-31G(d) dioxetane intermediate structures (A) and computed stabilities relative to (B) reactants $1+{ }^{1} \Delta_{\mathrm{g}}$ $\mathrm{O}_{2}$ (electronic) and $(C)$ each other $\left(G_{298}\right)$.

\section{Conclusions}

The photooxidation of heptamethine cyanines accompanies nearly any use of these broadly employed molecules. These studies, which centered on quantitative accounting of the major products and detailed computational studies, have provided key insights into this process. Cyanine photolysis leads to the regioselective cleavage of the cyanine polyene at two of the four possible positions. Only exogenously generated ${ }^{1} \mathrm{O}_{2}$, and not other common ROS, is capable of replicating this reaction pathway. We account for $\sim 70 \%$ of the molar balance of the starting cyanine, suggesting that at least this fraction goes through an energy transfer $/{ }^{1} \mathrm{O}_{2}$ pathway, while leaving open the possibility that the remainder reacts through other pathways (perhaps initiated by electron transfer from the triplet state).

Our computational analysis suggests that regioselective cleavage at only two positions of the polyene, $\mathrm{C} 2 / \mathrm{C}^{\prime}$ and $\mathrm{C} 2^{\prime} / \mathrm{C} 3^{\prime}$, can be interpreted as being a consequence of the overall energetics of the dioxetane intermediates. At the highest level examined, our calculations indicate that $\mathrm{O}_{2}$ addition is exothermic only at the observed sites $\left(\mathrm{C} 2 / \mathrm{C}^{\prime}\right.$ and $\left.\mathrm{C} 2^{\prime} / \mathrm{C} 3^{\prime}\right)$. By contrast, ${ }^{1} \mathrm{O}_{2}$ additions at the remaining two sites, $\mathrm{C}^{\prime} / \mathrm{C}^{\prime}$ and $\mathrm{C} 3^{\prime} / \mathrm{C}^{\prime}$, are less favorable and may actually be endothermic. Work in progress is currently exploring the reaction coordinate for singlet oxygen addition to form the dioxetane intermediates, itself a complex process in spite of numerous prior investigations. ${ }^{\mathbf{4 6 - 4 8}}$

The framework developed here should be of significant utility to efforts that seek to improve the photostability of cyanine fluorophores. Moreover, these studies provide a mechanistic foundation for our ongoing program harnessing the cyanine photooxidation reaction as the key step in a near-IR uncaging method. The systematic modification of the heptamethine cyanine scaffold is currently being pursued to access improved compounds for such applications.

\section{Methods}

\section{Experimental}

High-resolution LC/MS and MS/MS analyses were conducted on a Thermo-Fisher LTQ-Orbitrap-XL hybrid mass spectrometer system with an Ion MAX API electrospray ion source in positive ion mode. Flow injection analysis followed by collision-induced dissociation was utilized for MS/MS experiments. A quantitative HPLC assay to determine yields of 1, 2, and 6 was employed using an Agilent 1260 Infinity instrument. Samples were irradiated in HPLC vials using LED light sources obtained from Marubeni America Corporation or subjected to the reaction conditions in Tables 1 and 2.

\section{Quantum chemistry}

The calculations in this study were executed using the GAMESS $^{49}$ package. We have used the second-order MøllerPlesset perturbation theory (MP2) ${ }^{50-52}$ and density functional theory $(\mathrm{DFT})^{53}$ methods where, for the latter, the $\mathrm{B} 3 \mathrm{LYP}^{54,55}$ hybrid density functional (containing VWN5 functional) was utilized with a fine grid of 120 radial and 590 angular Lebedev points. Open-shell MP2-style calculations for the triplet oxygen 
species used the Z-averaged perturbation theory (ZAPT) ${ }^{56-58}$ flavor. The double-zeta $6-31 \mathrm{G}(\mathrm{d})^{59}$ and triple-zeta cc-pVTZ ${ }^{60}$ (spherical functions) basis sets were employed. Geometries were optimized to tight convergence (maximum Cartesian gradient $<1 \times 10^{-5}$ ) using analytic gradients and Hessians were computed seminumerically (double differences) using analytic gradients for all stationary points located. We note that Fig. S3† shows data evaluating the B3LYP and MP2 (including a variety of open-shell types) methods against benchmark and experiment for the hypothetical model reaction: ${ }^{3} \mathrm{O}_{2}+\mathrm{H}_{2} \mathrm{C}=\mathrm{CH}_{2} \rightarrow 2 \mathrm{H}_{2} \mathrm{C}=$ $\mathrm{O}$; all relevant references are provided therein. Based upon these results the ZAPT energy of the ${ }^{3} \Sigma_{\mathrm{g}}{ }^{-} \mathrm{O}_{2}$ molecule was used to determine reaction energies at the MP2 level of theory. Absolute energies of the ${ }^{1} \Delta_{\mathrm{g}} \mathrm{O}_{2}$ molecule were determined by adding the experimental ${ }^{3} \Sigma_{\mathrm{g}}{ }^{-} \rightarrow{ }^{1} \Delta_{\mathrm{g}}$ energy difference $\left(22.639 \mathrm{kcal} \mathrm{mol}^{-1}\right)^{61}$ to computed energies of the ${ }^{3} \Sigma_{\mathrm{g}}{ }^{-} \mathrm{O}_{2}$ system.

\section{Conflict of interest}

The authors declare no competing financial interest.

\section{Acknowledgements}

This project has been funded in whole or in part with federal funds from the National Cancer Institute, National Institutes of Health, under Contract No. HHSN261200800001E and by the Intramural Research Program of the National Institutes of Health, Center for Cancer Research, and the National Cancer Institute, National Institutes of Health. The content of this publication does not necessarily reflect the views or policies of the Department of Health and Human Services, nor does mention of trade names, commercial products, or organizations imply endorsement by the U.S. Government.

\section{References}

1 A. Diaspro, G. Chirico, C. Usai, P. Pamoino and J. Dobrucki, Photobleaching, in Handbook of Biological Confocal Microscopy, ed. J. B. Pawley, Springer, New York, 2006, pp. 690-702.

2 M. Levitus and S. Ranjit, Q. Rev. Biophys., 2011, 44, 123-151. 3 Q. S. Zheng, M. F. Juette, S. Jockusch, M. R. Wasserman, Z. Zhou, R. B. Altman and S. C. Blanchard, Chem. Soc. Rev., 2014, 43, 1044-1056.

4 J. Widengren and R. Rigler, Bioimaging, 1996, 4, 149-157.

5 I. Georgakoudi and T. H. Foster, Photochem. Photobiol., 1998, 67, 612-625.

6 T. Ha and P. Tinnefeld, Annu. Rev. Phys. Chem., 2012, 63, 595617.

7 J. V. Frangioni, Curr. Opin. Chem. Biol., 2003, 7, 626-634.

8 J. T. Alander, I. Kaartinen, A. Laakso, T. Patila, T. Spillmann, V. V. Tuchin, M. Venermo and P. Valisuo, Int. J. Biomed. Imaging, 2012, 2012, 1-26.

9 M. Henary and M. Mojzych, Stability and Reactivity of Polymethine Dyes, in Heterocyclic Polymethine Dyes: Synthesis, Properties and Applications, ed. L. Strekowski,
Topics in Heterocyclic Chemistry 14, Springer-Verlag, Berlin, 2008, p. 221.

10 R. R. Nani, J. B. Shaum, A. P. Gorka and M. J. Schnermann, Org. Lett., 2015, 17, 302-305.

11 A. P. Gorka, R. R. Nani and M. J. Schnermann, Org. Biomol. Chem., 2015, 132, 7584-7598.

12 A. P. Gorka, R. R. Nani, J. Zhu, S. Mackem and M. J. Schnermann, J. Am. Chem. Soc., 2014, 136, 1415314159.

13 D. Oushiki, H. Kojima, T. Terai, M. Arita, K. Hanaoka, Y. Urano and T. Nagano, J. Am. Chem. Soc., 2010, 132, 2795-2801.

14 M. T. Sun, H. Yu, H. J. Zhu, F. Ma, S. Zhang, D. J. Huang and S. H. Wang, Anal. Chem., 2014, 86, 671-677.

15 S. Lepaja, H. Strub and D. J. Lougnot, Z. Naturforsch., A: Phys. Sci., 1983, 38, 56-60.

16 G. W. Byers, S. Gross and P. M. Henrichs, Photochem. Photobiol., 1976, 23, 37-43.

17 A. Toutchkine, D. V. Nguyen and K. M. Hahn, Org. Lett., 2007, 9, 2775-2777.

18 B. R. Renikuntla, H. C. Rose, J. Eldo, A. S. Waggoner and B. A. Armitage, Org. Lett., 2004, 6, 909-912.

19 N. J. Patel, E. Manivannan, P. Joshi, T. J. Ohulchanskyy, R. R. Nani, M. J. Schnermann and R. K. Pandey, Photochem. Photobiol., 2015, DOI: 10.1111/php.12482.

20 P. Chen, J. Li, Z. G. Qian, D. S. Zheng, T. Okasaki and M. Hayami, Dyes Pigm., 1998, 37, 213-222.

21 X. Y. Chen, X. J. Peng, A. J. Cui, B. S. Wang, L. Wang and R. Zhang, J. Photochem. Photobiol., A, 2006, 181, 79-85.

22 A. Samanta, M. Vendrell, R. Das and Y. T. Chang, Chem. Commun., 2010, 46, 7406-7408.

23 E. Engel, R. Schraml, T. Maisch, K. Kobuch, B. Koenig, R. M. Szeimies, J. Hillenkamp, W. Baumler and R. Vasold, Invest. Ophthalmol. Visual Sci., 2008, 49, 1777-1783.

24 M. P. Samtsov, S. A. Tikhomirov, O. V. Buganov, K. N. Kaplevsky, D. G. Melnikov and L. S. Lyashenko, J. Appl. Spectrosc., 2009, 76, 783-790.

25 H. K. Ijuin, M. Yamada, M. Ohashi, N. Watanabe and M. Matsumoto, Eur. J. Mass Spectrom., 2008, 14, 17-25.

26 R. W. Redmond and J. N. Gamlin, Photochem. Photobiol., 1999, 70, 391-475.

27 F. Nifiatis, J. C. Athas, K. D. D. Gunaratne, Y. Gurung, K. M. Monette and P. J. Shivokevich, Open Spectrosc. J., 2011, 5, 1-12.

28 N. J. Turro, M. F. Chow and J. Rigaudy, J. Am. Chem. Soc., 1981, 103, 7218-7224.

29 E. L. Clennan and A. Pace, Tetrahedron, 2005, 61, 6665-6691. 30 V. A. Kuzmin, A. S. Tatikolov and Y. E. Borisevich, Chem. Phys. Lett., 1978, 53, 52-55.

31 J. P. Fouassier, D. J. Lougnot and J. Faure, Chem. Phys. Lett., 1975, 35, 189-194.

32 A. Toutchkine, V. Kraynov and K. Hahn, J. Am. Chem. Soc., 2003, 125, 4132-4145.

33 Q. Zheng, S. Jockusch, Z. Zhou and S. C. Blanchard, Photochem. Photobiol., 2014, 90, 448-454.

34 C. P. Chen, B. M. Zhou, D. H. Li and G. G. Xu, J. Photochem. Photobiol., A, 1995, 89, 25-29. 
35 M. S. Baker and J. M. Gebicki, Arch. Biochem. Biophys., 1984, 234, 258-264.

36 M. S. Chan, D. Xu, L. Guo, D. Y. Tam, L. S. Liu, M. S. Wong and P. K. Lo, Org. Biomol. Chem., 2015, 13, 7307-7312.

37 K. Y. Pu, A. J. Shuhendler and J. H. Rao, Angew. Chem., Int. Ed., 2013, 52, 10325-10329.

38 R. M. Uppu and W. A. Pryor, Anal. Biochem., 1996, 236, 242249.

39 R. S. Lepkowicz, O. V. Przhonska, J. M. Hales, J. Fu, D. J. Hagan, E. W. Van Stryland, M. V. Bondar, Y. L. Slominsky and A. D. Kachkovski, Chem. Phys., 2004, 305, 259-270.

40 S. Pascal, A. Haefele, C. Monnereau, A. Charaf-Eddin, D. Jacquemin, B. Le Guennic, C. Andraud and O. Maury, J. Phys. Chem. A, 2014, 118, 4038-4047.

41 P. A. Bouit, C. Aronica, L. Toupet, B. Le Guennic, C. Andraud and O. Maury, J. Am. Chem. Soc., 2010, 132, 4328-4335.

42 K. T. Lin and J. W. Silzel, Spectrochim. Acta, Part A, 2015, 142, 210-219.

43 F. Terenziani, O. V. Przhonska, S. Webster, L. A. Padilha, Y. L. Slominsky, I. G. Davydenko, A. O. Gerasov, Y. P. Kovtun, M. P. Shandura, A. D. Kachkovski, D. J. Hagan, E. W. van Stryland and A. Painelli, J. Phys. Chem. Lett., 2010, 1, 1800-1804.

44 M. Matsumoto, H. Kobayashi, J. Matsubara, N. Watanabe, S. Yamashita, D. Oguma, Y. Kitano and H. Ikawa, Tetrahedron Lett., 1996, 37, 397-400.

45 J. Sivaguru, M. R. Solomon, T. Poon, S. Jockusch, S. G. Bosio, W. Adam and N. J. Turro, Acc. Chem. Res., 2008, 41, 387-400. 46 A. A. Frimer, Chem. Rev., 1979, 79, 359-387.
47 E. L. Clennan and K. Nagraba, J. Am. Chem. Soc., 1988, 110, 4312-4318.

48 A. Maranzana, G. Ghigo and G. Tonachini, J. Am. Chem. Soc., 2000, 122, 1414-1423.

49 M. W. Schmidt, K. K. Baldridge, J. A. Boatz, S. T. Elbert, M. S. Gordon, J. H. Jensen, S. Koseki, N. Matsunaga, K. A. Nguyen, S. J. Su, T. L. Windus, M. Dupuis and J. A. Montgomery, J. Comput. Chem., 1993, 14, 1347-1363.

50 J. A. Pople, J. S. Binkley and R. Seeger, Int. J. Quantum Chem., 1976, 1-19.

51 G. D. Fletcher, M. W. Schmidt and M. S. Gordon, Adv. Chem. Phys., 1999, 110, 267-294.

52 C. M. Aikens, S. P. Webb, R. L. Bell, G. D. Fletcher, M. W. Schmidt and M. S. Gordon, Theor. Chem. Acc., 2003, 110, 233-253.

53 W. Kohn and L. J. Sham, Phys. Rev., 1965, 140, 1133-1138. 54 A. D. Becke, J. Chem. Phys., 1993, 98, 5648-5652.

55 P. J. Stephens, F. J. Devlin, C. F. Chabalowski and M. J. Frisch, J. Phys. Chem., 1994, 98, 11623-11627.

56 T. J. Lee and D. Jayatilaka, Chem. Phys. Lett., 1993, 201, 1-10. 57 T. J. Lee, A. P. Rendell, K. G. Dyall and D. Jayatilaka, J. Chem. Phys., 1994, 100, 7400-7409.

58 C. M. Aikens, G. D. Fletcher, M. W. Schmidt and M. S. Gordon, J. Chem. Phys., 2006, 124, 014107.

59 P. C. Harihara and J. A. Pople, Theor. Chim. Acta, 1973, 28, 213-222.

60 T. H. Dunning, J. Chem. Phys., 1989, 90, 1007-1023.

61 G. Herzberg and K. P. Huber, Molecular spectra and molecular structure. IV. Constants and diatomic molecules, Van Nostrand Reinhold, New York, London, 1979. 